\title{
An ambitious 5-year honors program in French universities: CMI-FIGURE
}

\author{
Ramona Barbour Eisen ${ }^{1}$, Yves Bertrand ${ }^{1}$, Lamine Boubakar ${ }^{2}$, Jean-Pierre Gesson ${ }^{1 *}$, Sylvie \\ Pautrot $^{1}$, Rodolphe Vauzelle ${ }^{1}$ \\ 1. University of Poitiers, Faculty of Fundamental and Applied Sciences \\ 2. University of Franche-Comté, Faculty of Sciences \\ * Corresponding author: jean-pierre.gesson@univ-poitiers.fr
}

Received: 26 January 2018; Accepted: 27 February 2018; Published: 30 April 2018

\begin{abstract}
In this paper, we will describe the Cursus Master en Ingénierie (CMI) program, as well as the Formation à I'InGénierie par des Universités de REcherche (FIGURE) university network, and analyze its development and place in the French higher education context. Overseen by the FIGURE university network since 2012, CMI is a 5-year academic program designed for the most ambitious students in systems engineering. In the fall of 2017, $107 \mathrm{CMI}$ programs recruited first-year students in 28 French universities. Key features of the frame of reference established by the FIGURE network are selection of students based on high school records and interviews, strong link with research from the beginning, $20 \%$ additional coursework compared to the supporting bachelors and masters, at least $25 \%$ of ECTS credits in applied learning situations, development of self-assessment skills and a compulsory international mobility. Accreditation of the university is granted by the network for 5 years. After completing a CMI program the students receive a master's degree from their home university and a national certificate co-delivered by the university and the network.
\end{abstract}

Keywords: honors; excellence; master; engineering; university; higher education; network; France

\section{Introduction}

Higher education in France, indeed the entire educational system, is based on the principle enshrined in the Code of Education of equal opportunity for all. Despite the central importance of equality, all studies on the subject show that the current French system is profoundly inegalitarian, perhaps the most inegalitarian of all OECD countries (CNESCO, 2016). Higher education in France, despite its underlying commitments, reflects this systemic inequality. In France, academic excellence in higher education is generally associated with the complex and highly selective "Grandes Ecoles" system and less with universities known for providing access to all. 
That said, French universities have always attracted talented students, increasingly through targeted programs (Ollivier De Leth \& Hogenstijn, 2017). One of the most recent and undoubtedly the most ambitious examples is the CMI-FIGURE (CMI referring to Cursus Master en Ingénierie i.e. Master of engineering curriculum; FIGURE to Formation à I'InGénierie par des Universités de REcherche i.e. the network of Engineering programs through research universities).

Guided by a desire to keep universities accessible to all, while fostering programs likely to attract ambitious students, in 2011 the French government launched a call for projects under the name IDEFI (translated as Innovative Programs Excellence Initiatives), with a budget of $€$ 150 million. "This call for projects aims to support emblematic and innovative higher education projects. The goal is to enhance teaching innovation by supporting a limited number of ambitious initiatives meeting high international standards. The projects must lay the ground for university programs of the future and promote new teaching approaches and new content. These innovations are expected to address issues of attractiveness, multidisciplinarity, student employability, links with research and pedagogical engineering." (ANR, 2011, first lines of presentation translated from French).

The project CMI-FIGURE, initially launched by 10 French universities, was the highest ranked of all applications with a budget of $€ 10$ million for the period of April 2012 to April 2019. Overseen by the FIGURE university network, the project offers academic programs designed for the most ambitious students, programs analogous to honors programs now being developed in Europe and worldwide (Wolfensberger, 2015) as defined by the EHC: Honors programs are selective study programs linked to higher education institutions. They are designed for motivated and/or gifted students who want to do more than the regular program offers. These programs have clear admission criteria and clear goals and offer educational opportunities that are more challenging and demanding than regular programs.

The CMI-FIGURE project drew on a study by the French AERES (Agency for the Evaluation of Research and Higher Education; which has since become the HCERES: High Council for the Evaluation of Research and Higher Education) on university training for engineering professions (Chabbal \& Menand, 2010). The goal of the CMI-FIGURE project is to train specialized experts qualified to hold upper management level (engineering) positions in a variety of fields, by responding to the expectations of the socioeconomic environment in terms of innovation and openness in multinational contexts. The term "engineering" is used in a very broad sense and applies to systems engineering. The scientific approach, based on knowledge in the areas such as mathematics and in particular computer science, applies to several domains of activity requiring creativity and innovation and involving a range of experts.

\section{The Cursus Master en Ingénierie (CMI) project and the FIGURE network}

Several aspects of the CMI project (translated as Master of Engineering Curriculum) represent significant innovation within the French higher education system. Of most significance, is the fact that for the first time a network of French universities has been authorized to deliver a national certificate corresponding to a specific academic program (the $\mathrm{CMI}$ ), collectively established by that network. To ensure consistency within the network, a procedure for accreditation and monitoring based on stringent international criteria was 
established. A 36-page frame of reference, updated yearly, was developed to help universities on the one hand and experts responsible for reviewing requests for accredited programs on the other. Accreditation is delivered by a specific commission for 5 years and includes a review after 2 years. After completing a CMI program, students receive a master's degree from their university of enrollment as well as a national certificate co-delivered by the FIGURE network and the university.

The goal of the $\mathrm{CMI}$ is to offer to a limited group of highly motivated and ambitious students a specific program which builds on existing bachelor and master's programs and adds $20 \%$ more credit hours starting in the first year (see table 1). CMI students are selected based on their secondary school academic records and admission interviews and in rare cases, after admission to university. The CMI differs in this respect from honors programs organized in other countries. That said, the guiding philosophy is identical to that of other honors programs.

Table 1. European Credit Transfer System (ECTS) distribution

\begin{tabular}{|l|l|l|l|}
\hline Period & ECTS Standard training & Additional 20\% ECTS & CMI Total ECTS \\
\hline Semester & 30 & 6 & 36 \\
\hline Year & 60 & 12 & 72 \\
\hline Bachelor & 180 & 36 & 216 \\
\hline Master & 300 & 60 & 360 \\
\hline
\end{tabular}

The $\mathrm{CMI}$ enhances existing curricula by offering a strong link with research, innovative pedagogy and obligatory international mobility. The following are CMI program guidelines set forth in the frame of reference:

- The internal research dimension relies on one or more nationally recognized research units within the participating universities. These units are most commonly joint research units involving well-known research organizations such as the CNRS, INSERM and INRA or research units internal to these organizations. (In France, research units are large structures with dozens and sometimes hundreds of staff members.) The number of students recruited in the first year of a given CMI is dependent upon staff available in the corresponding research unit or units (lecturers, researchers, engineers and PhD students). The average is currently $15 \mathrm{CMI}$ students per program.

- An appropriate balance (\% of ECTS credits) between academic subjects must be respected by the participating universities. The target is $50 \%$ for the specialization, $20 \%$ for core scientific subjects (mathematics, computer science \& physics), $10 \%$ for other subjects related to the domain of specialization and $20 \%$ for "ouverture sociale, économique et culturelle" (OSEC), translated as social, economic and cultural awareness. Participating universities must meet threshold requirements but are allowed a certain amount of freedom. For example, it would be possible to attribute $40 \%$ of a program's ECTS to specialized academic subjects, the additional percentage being redistributed in one or more of the other subjects.

- The CMI places a great deal of importance on the development of social, economic and cultural awareness (OSEC). For this reason, a specific "OSEC" reference document was developed to facilitate their inclusion in $\mathrm{CMI}$ programs. This document is 
organized around three central themes: languages, personal development and business knowledge:

- Languages emphasizes a minimum of a B2 level in English, or more specifically 785 on the TOEIC, is required to obtain the CMI certificate. Some universities require that this level be met before a student engages in mobility abroad even at a bachelor level. Knowledge of another foreign language is also encouraged;

- Personal development emphasizes different elements: expression and communication (French and English) transversal skills (computers and internet certification, applied learning situations, self-assessment); personal and career objectives (in the first year of study an academic path is established by the student, with the help of his or her program director, and is adapted as needed over the course of the program); general culture (fine arts \& literature) and knowledge of the major issues facing society (sustainable development, ethics, geopolitics);

- Business knowledge emphasizes general understanding which is both internal (functioning, rules, sociology) and external (geopolitical and socioeconomic contexts). Five specific business themes are central to a CMI: human resource management and administration, technology management and administration, organization of company life, project management and entrepreneurship.

- The program must include on average $25 \%$ applied learning situations: projects (design projects, integration projects, industrial projects), internships in laboratories and companies (minimum set at $20 \%$ ). One result of this is that the length of time students spend in companies is at least 8 months over the 5 years of the program (table 2).

Table 2. Applied learning for Bachelor (B1-B3) and Master (M1-M2) curricula

\begin{tabular}{|l|l|}
\hline Period & Activity \\
\hline Between B1 and B2 & 3 to 6 weeks in a company \\
\hline B2 & $50-60$ h project related to a laboratory (bibliography) \\
\hline B3 & 120 h integrated project \\
\hline $\begin{array}{l}\text { End of B3 or } \\
\text { between B3 and M1 }\end{array}$ & $\begin{array}{l}10 \text { weeks internship } \\
\text { (laboratory, company) }\end{array}$ \\
\hline M2 & 160 h integrated project \\
\hline End of M2 & 24-week internship \\
\hline
\end{tabular}

The ultimate goal of these different guidelines is to make the CMI a clearly identifiable certificate at the national and international level, guaranteeing quality through specific requirements while leaving a great deal of latitude to participating universities.

\section{The distribution of $\mathrm{CMI}$ programs in French universities}

The CMI started in September 2012, with 28 accredited CMI programs in 12 universities. The first cohort of students, having completed the full 5 years of study, graduated in October, 2017. Certain pioneer universities (Aix Marseille, Pierre-et-Marie Curie Paris, Paul-Sabatier Toulouse, Poitiers) started CMI programs in 2010 allowing them deliver the CMI certificate as early as 2015. In 2015, 22 graduates from 6 CMI programs in 4 universities were awarded the CMI certificate. The number of graduates included students having started the CMI in 2010 in 
their first year of study or in 2011 in their second year of study, some universities having accepted later enrollment. This was also the case in 2016 for 18 graduates from 5 universities. In 2017 the number of graduates was 76 (plus 12 potential graduates, pending validation of the English language requirements). In the future more meaningful data on professional integration or continuation to doctoral programs will be obtained and analyzed by the network based on data collected in each member university. Furthermore, a national association of $\mathrm{CMI}$ alumni will be created soon.

The number of accredited CMI programs has expanded over the years to a total of 112 programs in 28 universities in September 2017. The actual number of CMI programs open for first-year recruitment in 2017 was 107 due to insufficient enrollment in 5 programs (see table $3)$.

Table 3. Number of accredited universities and CMI programs

\begin{tabular}{|l|l|l|l|}
\hline Starting year & Universities & CMI accreditation & CMI total \\
\hline 2012 & 12 & 28 & 28 \\
\hline 2013 & 14 & 16 & 44 \\
\hline 2014 & 20 & 25 & 69 \\
\hline 2015 & 21 & 19 & 88 \\
\hline 2016 & 25 & 14 & 102 \\
\hline 2017 & 28 & 10 & 112 \\
\hline
\end{tabular}

The enrollment in CMI programs has grown along with the increase in the number of CMI programs. In the academic year 2017-2018 close to 3,000 students are enrolled in CMI programs. The number of accredited CMI programs is between 1 and 9 per university (see table 4). When several CMI programs exist within the same university a CMI coordinator oversees internal organization and external outreach. The CMI coordinator can organize classes involving all CMI students. These classes, mixing students from different CMI programs, are commonly offered during the first few years of study and help foster a sense of belonging to the CMI community. OSEC classes and workshops lend themselves particularly well to this type of activity. This sense of community is also promoted during specific events organized at the beginning of each academic year. Associations of CMI students are encouraged in each university under the umbrella of a national one (CMI France).

As noted earlier, the $\mathrm{CMI}$ focuses on systems engineering. Consequently, the $\mathrm{CMI}$ involves domains that are not traditionally associated with engineering programs in France. Most CMI programs fall within a specific area of activity related to a scientific discipline, but some CMI programs are related to other areas of activity (information and communication, sport, tourism and heritage, transportation and mobility and more recently history). Some programs combine different domains such as computer science and mathematics.

A fact sheet specifying the objectives of each CMI program is available on the FIGURE network's websites (www.reseau-figure.fr, www.figure-network.org). Each fact sheet includes information about career opportunities, the list of supporting research units and industrial and international partners. These program fact sheets are accompanied in some cases by 
associated job descriptions made available by the National Office of Information on Training and Professions (ONISEP, www.onisep.fr).

Table 4. Number of ongoing CMI programs per university (2017-2018)

\begin{tabular}{|l|l|l|l|}
\hline University & CMI & University & CMI \\
\hline Aix-Marseille & 9 & Montpellier & 8 \\
\hline Angers & 3 & Nantes & 4 \\
\hline Avignon et Pays du Vaucluse & 5 & Orléans & 1 \\
\hline Bordeaux & 6 & Paris Assas & 1 \\
\hline Bretagne Occidentale & 1 & Paris Nanterre & 1 \\
\hline Bretagne Sud & 2 & Paris Pierre-et-Marie Curie & 3 \\
\hline Cergy-Pontoise & 8 & Pau et Pays de I'Adour & 4 \\
\hline Franche-Comté & 8 & Poitiers & 6 \\
\hline La Rochelle & 7 & Reims Champagne-Ardennes & 2 \\
\hline Le Mans & 1 & Rennes 1 & 1 \\
\hline Lille 1 & 6 & Savoie Mont-Blanc & 3 \\
\hline Littoral Côte d'Opale & 1 & Strasbourg & 4 \\
\hline Lorraine & 1 & Toulouse 3 Paul-Sabatier & 8 \\
\hline Lyon 1 Claude-Bernard & 2 & Valenciennes & 1 \\
\hline
\end{tabular}

The number of scientific disciplines represented by the CMI in 2017-2018 is 18; it was 17 in 2016, 15 in 2015, 14 in 2014, 11 in 2013 and 9 in the founding year 2012. The most highly represented ones are those found in areas traditionally associated with engineering, but it is interesting to observe the spread of the concept in other sectors.

\section{Organization of the FIGURE network}

The FIGURE network is overseen by a piloting committee, a veritable board of directors made up of representatives of each member university. The piloting committee makes pedagogical and strategic decisions covering the entire scope of network actions, examines the network's operational procedures, makes decisions on implementing corrective action and is a creative force concerning evolutions in CMI programs already offered and the entry of new members into the network. The piloting committee acts on suggestions made by the executive office and different work groups. The executive office, composed of a limited number of members, deals with everyday business. It also establishes strategic approaches and drafts action proposals which it implements after validation by the piloting committee. Currently three other committees are involved in the governance of the network.

- The scientific and pedagogical committee enhances teaching within the network by making suggestions on topics shared by all CMI programs such as the alignment of experience, evaluation and pedagogy. Important themes such as a CMI student's progression through the curriculum to the delivery of the CMI certificate, projects and internships, entry into and exit from the curriculum are defined by this committee, which includes university representatives and outside experts. The 
committee is supported by work groups each created for a specific thematic area (ex: mathematics).

- The accreditation and monitoring committee approves or rejects new CMI program proposals, making recommendations when needed. After monitoring a newly created $\mathrm{CMI}$ program for 5 years, they decide whether or not and under what conditions to renew accreditation. This committee is composed of experts outside the network and members of the network's executive office.

- The strategic committee is in charge of providing a forward-looking vision of the needs and objectives of the $\mathrm{CMI}$ programs and fostering partnerships with actors in the private sector, in particular corporate groups and business clusters. As such, it is composed of outside professionals in charge of research, innovation and recruitment in their own organizations as well as members of the executive office.

The network also has an international relations commission made up of representatives from each of its member universities. The goal of this commission is to propose joint initiatives meant to help member universities with their international student recruitment procedures and outgoing student mobility.

Through these different bodies, the FIGURE network's role is to provide quality assurance for $\mathrm{CMI}$-accredited programs and to help them through the dissemination of best practices and training. To this end specific seminars are offered as well as an annual general assembly. The network also offers a methodology to implement a global quality assurance system in universities.

\section{Future outlook and conclusion}

The CMI has developed quickly over 5 years, now including $107 \mathrm{CMI}$-accredited programs in 18 specializations. The number of students per CMI program remains low (15 on average with significant variation from one $\mathrm{CMI}$ program to another). To a certain extent, this stems from their selective nature. There is, however, a potential for growth within the CMI programs which has not yet been fully exploited in part due to the lack of figures concerning employment rates and continuation to doctoral programs. It has been difficult to provide this information to potential students, as graduation from the program was not fully effective until 2017, resulting in a limited number of program graduates.

The CMI will remain a selective program aimed at the most ambitious students. The program has been designed to offer more diversity in France, based on a strong research support available in university (usually in connection with research organisms like CNRS, INSERM or INRA). So the CMI is closer to the international standard of master of engineering "with honors" than to the French system of "Grandes Ecoles" or Schools of Engineering. The latter prepare students to get a diploma of "ingénieur diplômé" but the CMI will also prepare students able to hold positions as engineers in a $21^{\text {st }}$ century economy (In France the "ingénieurs diplômés" represent only a part of all graduates holding an engineer job).

The question of opening the system to include accreditation of "CBI" (Cursus Bachelor en Ingénierie) certificates has been posed. This will potentially open the project to new students and universities. A university could be interested in setting up a $\mathrm{CBI}$ program rather than a full CMI with its strong research requirements. A potential student could wish to enroll in a 3- 
year program after completion of secondary school, rather than make a full 5-year commitment.

International openness is another priority. Initially the FIGURE network strongly recommended that programs include international mobility, then made it obligatory (three months, as a minimum) in 2015. Since then the minimum three-month requirement and a recommendation of semester-long mobility have been included in the frame of reference distributed to new $\mathrm{CMI}$ students. Given that outgoing student mobility most often takes place from the $3^{\text {rd }}$ year of study on, a significant rise in mobility can be expected in the short term. It is therefore essential that member universities cultivate existing European and international partnerships, in particular partnerships with research units and teaching departments. The FIGURE network can provide support in this area by signing framework agreements with other university networks and by participating in binational and European programs.

The FIGURE network has developed an accreditation procedure that respects international standards and supports quality assurance procedures recognized at the European and International level (the network is a member of the European Network for Accreditation of Engineering Education ENAEE). Central to the accreditation procedure is the respect for the frame of reference with its high standards that emphasize 21st century skills (van Eijl, Peeters, Moesker, Dillen, Pilot \& van Ginkel, 2017). This allows CMI programs to guarantee students quality training and successful professional integration in different domains.

\section{Acknowledgments}

Special thanks to Robert Chabbal and Alain Menand for their numerous and eminent contributions on this project.

\section{References}

ANR (Agence Nationale de la Recherche) (2011). Appel à projets "Initiatives d'excellence en formations innovantes" (IDEFI). Retreived from: http://www.agence-nationale$\underline{\text { recherche.fr/investissements- } d \text {-avenir/appels-a-projets/2011/initiatives-dexcellence-en- }}$ formations-innovantes-idefi/ (accessed 22 July 2017)

Chabbal, R. \& Menand, A. (2010). Formation universitaire au métier d'ingénieur. Retrieved from http://reseau-figure.fr/le-reseau-figure/documents-de-reference/ (accessed 22 July 2017)

CNESCO (Conseil National d'Évaluation du Système Scolaire) (2016). Inégalités sociales et migratoires. Comment l'école amplifie-t-elle les inégalités? Retrieved from: http://www.cnesco.fr/wp-content/uploads/2016/10/1610927_Rapport_Cnesco_Inegalites4.pdf (accessed 24 July 2017)

Ollivier De Leth, D. \& Hogenstijn M. (2017). Honors education in France - preliminary research results. Journal of the European Honors Council 1(1), 5, pp. 1-4 
Van Eijl, P., Peeters, T., Moesker, H., Dillen, A., Pilot, A. \& van Ginkel, S. (2017). Honors programs as forerunner for 21st century skills? Journal of the European Honors Council 1(2), 8, pp. 1-15.

Wolfensberger, M.V.C. (2015). Talent development in European higher education. Honors Programs in the Benelux, Nordic and German-Speaking Countries. Heidelberg: Springer. https://doi.org/10.1007/978-3-319-12919-8 